\title{
RECRUITMENT LIMITATION CONSTRAINS LOCAL SPECIES RICHNESS AND PRODUCTIVITY IN DRY GRASSLAND
}

\author{
M. Zeiter, ${ }^{1}$ A. Stampfli, and D. M. Newbery \\ Institute of Plant Sciences, University of Bern, Altenbergrain 21, CH-3013 Bern, Switzerland
}

\begin{abstract}
Species coexistence and local-scale species richness are limited by the availability of seeds and microsites for germination and establishment. We conducted a seed addition experiment in seminatural grassland at three sites in southern Switzerland and repeated the experiment in two successive years to evaluate various circumstances under which seed limitation and establishment success affect community functioning. A collection of 144000 seeds of 22 meadow species including grasses and forbs of local provenance was gathered, and seeds were individually sown in a density that resembled natural seed rain. The three communities were seed limited. Three years after sowing, single species varied in emergence $(0-50 \%)$, survival (0-69\%), and establishment rates (0-27\%). One annual and 13 perennial species reached reproductive stage. Low establishment at one site and reduced growth at another site indicated stronger microsite limitation compared to the third site. Recruitment was influenced by differences in abiotic environmental conditions between sites (water availability, soil minerals) and by within-site differences in biotic interaction (competition). At the least water-limited site, sowing resulted in an increase in phytomass due to establishment of short-lived perennials in the second and third years after sowing. This increase persisted over the following two years due to establishment of longer-lived perennials. After sowing in a wetter year with higher phytomass, however, productivity did not increase, because higher intensity of competition in an early phase of establishment resulted in less vigorous plants later on. Due to the generally favorable weather conditions during this study, sowing year had a small effect on numbers of established individuals over all species. Recruitment limitation can thus constrain local-scale species richness and productivity, either by a lack of seeds or by reduced seedling growth, likely due to competition from the established vegetation.
\end{abstract}

Key words: colonization; ecosystem functioning; germination; invasibility; meadow restoration; Mesobromion; microsite limitation; regeneration; seed limitation; seedling establishment; sowing experiment; species composition.

\section{INTRODUCTION}

In species coexistence theory (Barot 2004), competition-colonization trade-off and lottery models of multispecies dynamics employ the concept of seed limitation. At a local scale, coexistence can only be achieved when at least some of the component species are seed limited. Seed addition experiments have been used to test for seed limitation, and several recent studies have shown that many ecological communities are unsaturated with species, such that their species richness is constrained by local ecological processes (i.e., competition) and availability of seeds (Tilman 1997, Zobel et al. 2000, Foster and Tilman 2003, Foster et al. 2004). However, as few field studies have been conducted for a sufficient duration to determine whether or not self-sustaining populations were successfully established (Turnbull et al. 2000), the role of seed limitation may have been overestimated (Zobel and Kalamees 2005).

Manuscript received 10 June 2005; revised 14 September 2005; accepted 30 September 2005. Corresponding Editor: D. P. C. Peters.

${ }^{1}$ E-mail: michaela.zeiter@ips.unibe.ch
Seed limitation might influence primary productivity of a community, because any process that alters the composition and/or diversity of a community also alters community processes. Whereas some studies in grasslands have found effects of seed addition on cover (Tilman 1997) or productivity (Foster and Dickson 2004, Foster et al. 2004), others have found none (Wilsey and Polley 2003, Mouquet et al. 2004). It is thus unclear under what set of conditions local productivity in grasslands would be expected to be constrained by seed availability, and in general, under what habitat conditions local colonization dynamics, species coexistence, and species richness are determined by the availability of colonists rather than niche availability (Foster et al. 2004).

The restoration of formerly species-rich meadows that have gone through successional changes during many years of abandonment is faced with the problems of insufficient seeds in local seed banks and long-distance seed dispersal (Stampfli and Zeiter 1999, Kupferschmid et al. 2000). The successful reestablishment of species is dependent upon the availability of seeds and/or favorable microsites, small-scale sites suitable for germination and establishment of seedlings (Eriksson and Ehrlen 
1992). Apart from dispersal and longevity of seeds, production and predation of seeds also can constrain seed availability. Microsite limitation, i.e., restricted niche availability, may be due to local biotic interactions (e.g., competition) or unsuitable abiotic habitat conditions (e.g., soil characteristics and unfavorable weather conditions for germination and establishment).

In 1998 we began a seed-addition experiment in seminatural dry grasslands at three sites in southern Switzerland to investigate the likelihood of reestablishment of 22 meadow species in mown sites that had suffered a reduction in species richness due to abandonment. As recruitment of grassland individuals to the adult stage seems to be a rare event (Silvertown and Dickie 1980), seedlings are probably highly susceptible to temporal variation in environmental conditions, and results of one-time seed additions may be confounded with the weather conditions in the year of sowing. The experiment was therefore repeated in two successive years.

The objectives of this study were to answer the following questions: (1) Is species establishment more limited by seed or microsite availability? (2) Are the species richness and productivity of dry grasslands seed limited? (3) Under what habitat conditions do seed limitation and establishment success determine community functioning? (4) Does establishment success and seed limitation depend on the weather conditions of the year of sowing?

\section{Material And Methods}

\section{Study sites}

Three experimental sites were selected in the lower montane zone in Ticino, southern Switzerland, in dry, nutrient-poor meadows (Mesobromion type sensu Ellenberg 1996) that have declined in species density during intermittent periods of abandonment over 1-3 decades. Poma and San Giorgio are close to one another (distance $5 \mathrm{~km}$ ); Negrentino is $62 \mathrm{~km}$ away from the other two sites. The climate is temperate-humid and shows relatively high means of annual precipitation, $\sim 1300 \mathrm{~mm}$ at Negrentino and $\sim 1900 \mathrm{~mm}$ at the two other sites (Walter and Lieth 1964).

Negrentino $(\mathrm{N})$, located in Valle di Blenio $(820 \mathrm{~m}$ above sea level [asl], $46^{\circ} 27^{\prime} 40^{\prime \prime} \mathrm{N}, 8^{\circ} 55^{\prime} 30^{\prime \prime} \mathrm{E}$ ) on a southfacing slope with a mean inclination of $19^{\circ}$, has been regularly mown by local farmers twice yearly, around the end of June and in September. Mowing was stopped in 1988 when the site was fenced and an experiment to study changes in species composition was established in close proximity (Stampfli 1992b, Stampfli and Zeiter 2004). Between 1988 and 1998, Brachypodium pinnatum strongly increased, its cover reaching $>75 \%$ in most of the area, and species richness decreased.

Poma (P), located at Monte Generoso (990 m asl, $\left.45^{\circ} 53^{\prime} 56^{\prime \prime} \mathrm{N}, 9^{\circ} 00^{\prime} 54^{\prime \prime} \mathrm{E}\right)$ on a southwest-facing slope with an inclination of $16^{\circ}$, had been mown by local farmers until 1968, when it was completely abandoned.
In 20 years, the vegetation changed into a species-poor Brachypodium pinnatum-dominated grassland with abundant geophytes, surrounded by patches of shrubs and trees, mainly of Corylus avellana and Betula pendula. In 1988, the site was fenced and regular mowing was resumed in early July, but species composition did not change much over 10 years (Stampfli and Zeiter 1999).

San Giorgio (S) is located at Monte San Giorgio (950 $\mathrm{m}$ asl, $\left.45^{\circ} 54^{\prime} 27^{\prime \prime} \mathrm{N}, 8^{\circ} 57^{\prime} 19^{\prime \prime} \mathrm{E}\right)$ on a southwest-facing slope with an inclination of $17^{\circ}$. Hay-making and grazing had been common practices until about 1955 (Stampfli et al. 1994). Abandonment over approximately three decades and a fire in 1965 favored the spread of the tussock-forming grass Molinia arundinacea, which became the dominant species in patches surrounded by small trees of Ostrya carpinifolia, Quercus pubescens, Betula pendula, and Sorbus aria. Since 1988 regular mowing with a scythe in early August (Stampfli 1992a) has resulted in reversed dominance of grasses: $M$. arundinacea was replaced by Danthonia alpina.

Some soil characteristics distinctly differed between one and the other sites. Negrentino showed higher available water capacity, San Giorgio a higher clay and available calcium content, and Poma a lower $\mathrm{pH}$ and a higher available aluminum content (Appendix A).

Species names follow Lauber and Wagner (1996).

\section{Seed addition experiment}

Seeds of five graminoids and 17 forbs representing a seed mass spectrum over a 330 -fold range were selected from the community species pools of the three experimental sites (Appendix B). In each of two years, 1998 and 1999, seeds were collected at random in July as mixed samples of seeds from 50-1000 mature inflorescences of at least 30 individuals growing in an area of $\sim 400 \mathrm{~m}^{2}$. Seeds were cleaned and stored at room temperature until sowing in September. Seed mass per species and year was determined by 10 sets of 100 seeds, and differences between years were tested using Student's $t$ test. Seed quality was determined in germination tests (Appendix B) that were started in the laboratory in August 1998 or September 1999.

At each experimental site, 10 blocks were established. Every block was divided in two parts for addition of seeds in 1998 or 1999 . In each part, a plot of $60 \times 90 \mathrm{~cm}$ for addition of seeds and a control plot of $60 \times 30 \mathrm{~cm}$ were established. Plots were separated by an interspace of at least $15 \mathrm{~cm}$. Seed addition was started after mowing in mid-September. One hundred seeds of 24 populations (21 species and Bromus erectus from three origins) were added per plot: for each population, one set of 10 individual seeds was randomly allocated in each of 10 subplots, thus 2400 seeds in each plot. Seeds were dropped individually onto the ground from a height of $\sim 5 \mathrm{~cm}$ using forceps and a board with regularly spaced holes (see Plate 1), resulting in a density of one seed per $2.25 \mathrm{~cm}^{2}$ (4444 seeds $\left./ \mathrm{m}^{2}\right)$. This quantitatively resembles a seed rain in seminatural meadows, one of ideally high 
TABle 1. Performance of 22 species sown at three grassland sites in southern Switzerland (N, Negrentino; P, Poma; and S, San Giorgio) three years after sowing in 1998 and 1999: emerged seedlings in sown (s) and control (c) plots, established individuals, growth of surviving individuals, and cumulative number of flowering plants.

\begin{tabular}{|c|c|c|c|c|c|c|c|c|c|}
\hline \multirow[b]{3}{*}{ Species } & \multicolumn{6}{|c|}{ No. emerged seedlings/unit area $\dagger$} & \multirow{2}{*}{\multicolumn{3}{|c|}{$\begin{array}{l}\text { No. established } \\
\text { seedlings/plot }\end{array}$}} \\
\hline & \multicolumn{2}{|c|}{$\mathrm{N}$} & \multicolumn{2}{|c|}{$\mathrm{P}$} & \multicolumn{2}{|c|}{$\mathrm{S}$} & & & \\
\hline & s & $\mathrm{c}$ & $\mathrm{s}$ & $\mathrm{c}$ & s & $\mathrm{c}$ & $\mathrm{N}$ & $\mathrm{P}$ & $\mathrm{S}$ \\
\hline Agrostis capillaris & 10 & 3 & 4 & - & 17.5 & - & $4.6^{\mathrm{a}}$ & $0.2^{\mathrm{b}}$ & $0.2^{\mathrm{b}}$ \\
\hline Anthyllis vulneraria & 45.5 & 3 & 45 & - & 50.5 & - & $15.5^{\mathrm{a}}$ & $2.0^{\mathrm{c}}$ & $5.6^{\mathrm{b}}$ \\
\hline Asphodelus albus & 20 & - & 13 & 0 & 22.5 & - & $13.9^{\mathrm{b}}$ & $7.0^{\mathrm{c}}$ & $20.3^{\mathrm{a}}$ \\
\hline $\begin{array}{l}\text { Brachypodium } \\
\text { pinnatum }\end{array}$ & 21 & - & 18.5 & 0 & 24.5 & - & $6.1^{\mathrm{b}}$ & $0.3^{\mathrm{c}}$ & $9.3^{\mathrm{a}}$ \\
\hline Bromus erectus & 56.3 & 0 & 36.7 & - & 59.3 & - & $26.3^{\mathrm{a}}$ & $3.5^{\mathrm{c}}$ & $15.9^{\mathrm{b}}$ \\
\hline Carex flacca & 0 & - & 0 & - & 0 & - & 0 & 0 & 0 \\
\hline Centaurea nigrescens & 46 & 0 & 33.5 & 0 & 57.5 & 0 & $29.4^{\mathrm{b}}$ & $12.0^{\mathrm{c}}$ & $38.9^{\mathrm{a}}$ \\
\hline Danthonia alpina & 6.5 & - & 2.5 & - & 30 & 15 & $3.7^{\mathrm{b}}$ & $1.2^{\mathrm{c}}$ & $8.1^{\mathrm{a}}$ \\
\hline $\begin{array}{l}\text { Dianthus } \\
\text { carthusianorum }\end{array}$ & 47 & - & 35 & - & 63.5 & 0 & $34.6^{\mathrm{a}}$ & $12.2^{\mathrm{b}}$ & $2.5^{\mathrm{c}}$ \\
\hline Dorycnium herbaceum & 11.5 & - & 7 & - & 15 & - & $0.3^{\mathrm{b}}$ & $0.3^{\mathrm{b}}$ & $5.0^{\mathrm{a}}$ \\
\hline Galium rubrum & 29 & 0 & 10 & - & 39 & - & $16.6^{\mathrm{a}}$ & $1.0^{\mathrm{c}}$ & $4.8^{\mathrm{b}}$ \\
\hline $\begin{array}{l}\text { Helianthemum } \\
\text { nummularium }\end{array}$ & 86 & 67.5 & 13 & 0 & 28.5 & 0 & $10.6^{\mathrm{a}}$ & $1.6^{\mathrm{b}}$ & $11.2^{\mathrm{a}}$ \\
\hline Hypochaeris radicata & 57 & 4.5 & 26.5 & - & 52.5 & - & $18.1^{\mathrm{a}}$ & $1.1^{\mathrm{c}}$ & $3.2^{\mathrm{b}}$ \\
\hline Peucedanum oreoselinum & 15.5 & - & 12 & - & 24 & - & $9.3^{\mathrm{b}}$ & $6.8^{\mathrm{b}}$ & $16.8^{\mathrm{a}}$ \\
\hline Phyteuma betonicifolium & $23^{\mathrm{NS}}$ & 15 & $104.5^{\mathrm{NS}}$ & 109.5 & 11.5 & - & $3.1^{\mathrm{a}}$ & $1.5^{\mathrm{b}}$ & $0.1^{\mathrm{c}}$ \\
\hline Plantago lanceolata & 51 & 33 & 26 & - & 60 & - & $9.4^{\mathrm{b}}$ & $10.5^{\mathrm{b}}$ & $27.0^{\mathrm{a}}$ \\
\hline Primula veris & 30.5 & 0 & 18 & - & 54 & 0 & $18.2^{\mathrm{a}}$ & $0.8^{\mathrm{b}}$ & $21.2^{\mathrm{a}}$ \\
\hline $\begin{array}{l}\text { Rhinanthus } \\
\quad \text { alectorolophus }\end{array}$ & 39 & 0 & 6.5 & - & 22 & - & 0 & 0 & 0 \\
\hline Sanguisorba minor & 35.5 & 7.5 & 20 & 0 & 62 & 0 & $6.7^{\mathrm{b}}$ & $3.1^{\mathrm{c}}$ & $28.9^{\mathrm{a}}$ \\
\hline Scabiosa columbaria & 39.5 & 0 & 21.5 & - & 42.5 & - & $20.3^{\mathrm{a}}$ & $2.7^{\mathrm{b}}$ & $15.9^{\mathrm{a}}$ \\
\hline Silene nutans & 90 & 40.5 & 26 & 3 & 52.5 & - & $14.2^{\mathrm{a}}$ & $6.0^{\mathrm{b}}$ & $0.9^{\mathrm{c}}$ \\
\hline Thalictrum minus & 21 & - & 11.5 & - & 28 & - & $11.1^{\mathrm{b}}$ & $3.4^{\mathrm{c}}$ & $21.5^{\mathrm{a}}$ \\
\hline
\end{tabular}

Notes: Lowercase superscripts $(\mathrm{a}-\mathrm{c}$ and $\mathrm{x}-\mathrm{z})$ indicate significantly different means $(P<0.05)$; NS refers to a nonsignificant difference between plots within sites.

$\dagger$ Median values from 20 plots; values for control plots $\left(0.18 \mathrm{~m}^{2}\right.$ in size) are corrected to unit area of $0.54 \mathrm{~m}^{2}$ (the size of sown plots). A zero indicates that seedlings emerged in a few plots but median $=0$; a dash indicates no seedlings emerged.

\$ Mean number established out of 100 sown seeds. Plot size here (and for number of flowering plants) is $0.54 \mathrm{~m}^{2}$.

$\S$ The $M$ (growth measurements) column indicates whether growth measurements were based on length of longest shoot and number of shoots (v) or number of leaves (b).

evenness. Sowing was alternated between sites in order to achieve similar mean sowing dates in both years (29 September 1998, 24-25 September 1999). Results concerning Bromus erectus in sown plots are means over three seed origins. Origin effects on establishment are the subject of another paper (M. Zeiter, A. Stampfli, and D. M. Newbery, unpublished manuscript).

Individuals that emerged from the total of 144000 added seeds were regularly checked over the 36 mo following sowing. Seedling emergence and subsequent survival was recorded at intervals of 1-3 mo. Every seedling was marked with a colored ringlet, and its position was mapped on a grid. Later, the complete history of each individual was compiled from the maps. A few individuals died before identification (1.7\% of all emerged seedlings). After recording the length of the longest shoot and number of shoots or leaves twice per year before mowing in June/July and September/ October, individuals were clipped at $5 \mathrm{~cm}$ above the ground surface. Seedling phytomass was pooled per plot and dried at $80^{\circ} \mathrm{C}$ for $24 \mathrm{~h}$. In comparisons of species' performances at the three sites, length $\times$ number of shoots or length of shoot $\times$ number of leaves were used as measures of growth (Table 1), as phytomass values were not available for individuals $<5 \mathrm{~cm}$ tall. Phytomass measurements were used to determine the proportion of sown individuals on total phytomass of the communities. Censuses of the first-year cohort, sown in 1998 at Negrentino, were extended until autumn 2003 in order to achieve a five-year perspective of the population dynamics. In comparisons of species' performances at the three sites, the number of emerged seedlings and the number of established individuals had to be corrected for seedlings that emerged spontaneously from the seed bank in the sown plots. Every sown plot was divided into three subplots of the same size as the control plot. The number of seedlings that emerged in a corresponding control plot was subtracted from each number of seedlings that emerged in subplots. Subplots for which the correction resulted in negative numbers or larger numbers than those of the seeds sown were excluded. Seedling numbers of plots with one subplot excluded were estimated on the basis of two subplots. In plots with more than one subplot excluded, number of 
TABLE 1. Extended.

\begin{tabular}{|c|c|c|c|c|c|c|}
\hline \multicolumn{3}{|c|}{ Growth $(\mathrm{cm})$} & \multirow[b]{2}{*}{$M \S$} & \multicolumn{3}{|c|}{$\begin{array}{l}\text { Cumulative } \\
\text { no. flowering } \\
\text { plants/plot }\end{array}$} \\
\hline $\mathrm{N}$ & $\mathrm{P}$ & $\mathrm{S}$ & & $\mathrm{N}$ & $\mathrm{P}$ & $\mathrm{S}$ \\
\hline 80.4 & 56.5 & 2.9 & $\mathrm{v}$ & 1.2 & 0 & 0 \\
\hline $137.1^{x}$ & $6.9^{y}$ & $9.8^{\mathrm{y}}$ & b & 19.2 & 0 & 0 \\
\hline $16.7^{x}$ & $4.3^{\mathrm{y}}$ & $6.0^{\mathrm{y}}$ & b & 0 & 0 & 0 \\
\hline 30.8 & 13.4 & $11.7^{\mathrm{y}}$ & $\mathrm{v}$ & 0 & 0 & 0 \\
\hline $37.2^{\mathrm{x}}$ & $11.3^{\mathrm{y}}$ & $6.1^{\mathrm{z}}$ & $\mathrm{v}$ & 0.1 & 0 & 0 \\
\hline $227.0^{x}$ & $16 \overline{6} 3^{x}$ & $30.9^{y}$ & b & 15.1 & $\begin{array}{l}0 \\
5.3\end{array}$ & $\begin{array}{l}0 \\
2.1\end{array}$ \\
\hline $19.1^{\mathrm{x}}$ & $16.1^{\mathrm{x}}$ & $8.1^{\mathrm{y}}$ & $\mathrm{v}$ & 0 & 0 & 0 \\
\hline $24.7^{\mathrm{x}}$ & $21.8^{x}$ & $1.6^{\mathrm{y}}$ & $\mathrm{v}$ & 1.8 & 0.5 & 0 \\
\hline 5.8 & 3.5 & 6.7 & $\mathrm{v}$ & 0 & 0 & 0 \\
\hline $204.6^{\mathrm{x}}$ & $13.7^{y}$ & $2.6^{\mathrm{z}}$ & $\mathrm{v}$ & 13.7 & 0.1 & 0 \\
\hline $58.7^{\mathrm{x}}$ & $2.3^{\mathrm{Z}}$ & $4.2^{\mathrm{y}}$ & $\mathrm{v}$ & 2.5 & 0 & 0 \\
\hline $76.9^{\mathrm{x}}$ & $119.7^{\mathrm{x}}$ & $11.0^{y}$ & $\mathrm{~b}$ & 14.3 & 0.6 & 0 \\
\hline $33.4^{\mathrm{x}}$ & $17.4^{\mathrm{y}}$ & $8.3^{\mathrm{z}}$ & b & 0 & 0 & 0 \\
\hline $4.7^{\mathrm{x}}$ & $2.5^{\mathrm{y}}$ & 0.9 & b & 0 & 0 & 0 \\
\hline $85.9^{\mathrm{x}}$ & $57.7^{\mathrm{y}}$ & $15.5^{\mathrm{z}}$ & b & 4.3 & 1.9 & 0.1 \\
\hline $7.9^{\mathrm{x}}$ & $2.8^{\mathrm{z}}$ & $3.7^{\mathrm{y}}$ & b & 0.2 & 0 & 0 \\
\hline- & - & - & - & 22.0 & 3.1 & 6.6 \\
\hline $37.2^{\mathrm{x}}$ & $16.8^{\mathrm{y}}$ & $17.4^{\mathrm{y}}$ & b & 0.1 & 0.1 & 0 \\
\hline $14.8^{\mathrm{x}}$ & $3.5^{\mathrm{y}}$ & $2.7^{\mathrm{y}}$ & $\mathrm{v}$ & 8.6 & 0.2 & 0 \\
\hline $4.6^{\mathrm{y}}$ & $7.1^{\mathrm{x}}$ & 1.2 & $\mathrm{v}$ & 0 & 0.2 & 0 \\
\hline $9.3^{x}$ & $4.7^{\mathrm{y}}$ & $5.6^{\mathrm{y}}$ & b & 0 & 0 & 0 \\
\hline
\end{tabular}

emerged seedlings was set to missing. Phytomass of individuals established from seed of those plots was estimated by the mean number of emerged seedlings of all other plots of the corresponding site and sowing year. Therefore phytomass values of four (out of 20) plots of Helianthemum nummularium, three plots of Phyteuma betonicifolium, and eight plots of Silene nutans at Negrentino were corrected, and phytomass values of nine plots of $P$. betonicifolium at Poma were likewise corrected.

\section{Habitat quality and weather conditions}

Productivity, gap proportion and quality, and radiation were selected as measures of habitat quality at the level of plots because light is presumably the major limiting resource for seedling establishment.

The vegetation in the plots was clipped at $5 \mathrm{~cm}$ above the ground surface in the first half of July and in the second half of September. The harvested phytomass was determined after drying at $80^{\circ} \mathrm{C}$ for 24 hours. Productivity was defined as mean annual dry mass across three years after sowing, measured in the control plots. In April of the first year after sowing, gap proportion and quality were sampled with a pin at 54 points, located in the centers of all $10 \times 10 \mathrm{~cm}$ quadrats within the sown plots. Gap proportion was defined as the proportion of points without vegetation contact below $1.5 \mathrm{~cm}$ above ground. Gap quality was determined by the presence or absence of litter. Bare ground was indicated by a gap without litter cover. Shading from surrounding trees and mountains was estimated using hemispherical photographs taken horizontally from a self-leveling mount at a height of $24 \mathrm{~cm}$ above the ground surface and software for image analysis (HemiView version 2.1, Delta-T, Cambridge, UK). Two sets of nine photographs were taken per site, one before and one after leaf fall, arranged in a grid covering all experimental plots. The first was used to estimate the potential global radiation for May-October, the latter for November-April, and the sum of both estimates was used to approximate annual values. From the nine values of potential global radiation per site, potential global radiation for every individual plot was estimated by interpolation. All measures of habitat quality significantly differed between sites (Appendix A), but not between years, except for Negrentino, where plots selected for seed addition in 1998 showed $24.7 \%$ less productivity than those in 1999.

Daily records of precipitation since 1893 from a weather station located at Comprovasco (MeteoSwiss Zürich), at a distance of $1 \mathrm{~km}$ from the Negrentino site, showed relatively wet conditions from September 1998 to December 2002. In 2003, however, the spring was dry and was followed by an exceptional drought from 12 May to 30 June.

In order to identify periods of limited water availability, rain and soil water potential $\left(\psi_{\text {soil }}\right)$ were measured at all sites by means of a rain gauge (ARG100, Environmental Measurements, Sunderland, UK) and a soil moisture sensor (equitensiometer EQ1 at $\mathrm{P}, \mathrm{EQ} 2$ at $\mathrm{N}$ and S; Delta-T, Cambridge, UK), installed at $5 \mathrm{~cm}$ below ground in the sunniest places at each site. Measurements, recorded hourly with data loggers (DL2e, Delta-T, Cambridge, UK, at N and P; DataHog2, Skye Instruments, Llandrindod Wells, UK, at S) were started in April 1999 (rain and soil moisture at N), in December 1999 (rain at P and S) and in December 2000 (soil moisture at $\mathrm{P}$ and $\mathrm{S}$ ).

Daily precipitation in the years 2000-2003 was correlated between sites, the nearest ones showing strongest correlation $(n=1211,241$ values missing; S$\mathrm{P}, r_{\mathrm{s}}=0.91 ; \mathrm{S}-\mathrm{N}, r_{\mathrm{s}}=0.71 ; \mathrm{P}-\mathrm{N}, r_{s}=0.70$, Spearman coefficients). In the relatively wet year of 2000, the annual precipitation sum at one site $(\mathrm{N}, 1732 \mathrm{~mm})$ was clearly lower than at the two other sites (S, 2548; P, 2609 $\mathrm{mm})$ due to "drier" summer months. Less rain was recorded at San Giorgio in June 2001 than at the two other sites.

Simulated soil water potentials, based on weather measurements of precipitation, air temperature, and humidity, and wind speed at Comprovasco and calibrated with soil water potentials in the summers 2000 and 2001 measured at Negrentino revealed continuously moist conditions for 1999 (dry conditions, $\psi_{\text {soil }}<-100$ $\mathrm{kPa}$ for $5 \mathrm{~h}$ ) and intermittently dry conditions for 1998 $\left(\psi_{\text {soil }}<-100 \mathrm{kPa}\right.$ for $\left.1448 \mathrm{~h}\right)$ across the growing season (March to October) preceding seed addition. Between 
December 2000 and December 2002, the soil never dried to $\psi_{\text {soil }}<-200 \mathrm{kPa}$, except briefly during summer at Poma (five days in 2001) and San Giorgio (15 days in 2001 , four days in 2002). In summer 2003, however, this threshold was surpassed for 57 days at Poma, 73 days at Negrentino, and 138 days at San Giorgio.

\section{Data analysis}

The performance of the 22 species at the three sites was analyzed for every species separately using GENSTAT 6.0 (Payne 2000). The design was a two-factor split-plot arrangement with 10 replicates. The factor site included three levels, and year of sowing included two levels. The design had two strata: (a) site $\times$ block level, $n$ $=30$ with block nested within site, and (b) site $\times$ block $\times$ plot level, $n=60$ with plot (year of sowing) nested within block. The growth variables were log-transformed and then analyzed using ANOVA. Generalized linear modeling (GLM), with the binomial distribution and logit-link function, was employed for the analysis of germination and survival rates. The response variables were the number of germinated seeds (binomial totals = 100 ) or the number of surviving individuals (binomial totals $=$ number of emerged seedlings). Although standard GLM cannot analyze split-plot designs with binomial data because it allows only one error term, in the analysis of deviance, effects can be tested against the appropriate error term by a quasi- $F$ test which is based on the ratio of deviances divided by their degrees of freedom, just as an $F$ test in an ordinary analysis of normally distributed data is based on the ratio of variances (McCullagh and Nelder 1989, Egli and Schmid 2001). Accumulated analysis of deviance tables were produced in the same way as the ANOVA tables for the general linear regression: the ratio of mean deviances was used for quasi- $F$ tests (quasi- $F$ is the mean deviance of a factor divided by the mean deviance of the residual), and the residuals were built up from the interactions of block and year (plot).

At every site, multiple regression using backward selection was applied to reveal the environmental determinants of seedling emergence, survival, and growth, using sums or means over all species, as appropriate.

The effect of sowing and year of sowing on productivity (phytomass per unit area) at Negrentino was tested using ANOVA with blocking.

Seed limitation, indicated by a higher number of seedlings per unit area in sown compared to control plots, was tested for every species individually using Mann-Whitney $U$ tests.

\section{RESULTS}

Seedlings of 6-14 of the 22 sown species emerged in the control plots at the three sites, but all sown species showed a significantly higher density of emerged seedlings in sown plots compared to control plots at all three sites, except Carex flacca, which showed almost no seedling emergence at all sites and Phyteuma betonicifolium, which was not augmented by sowing at two sites
(Table 1). Augmentation was small for Helianthemum nummularium, Plantago lanceolata, Silene nutans, and Danthonia alpina at single sites. Fourteen species reached reproductive stage within three years. Six species (Primula veris, H. nummularium, Agrostis capillaris, Dianthus carthusianorum, $P$. betonicifolium, and $S$. nutans) did not exceed a height of $3 \mathrm{~cm}$ and a density of two individuals per plot at one or two sites (Table 1).

Two years after sowing, the density of individuals established from sown seeds was higher than the density of recruits in control plots (N, 711 vs. 438 recruits $/ \mathrm{m}^{2} ; \mathrm{P}$, 175 vs. 28 recruits $/ \mathrm{m}^{2} ; \mathrm{S}, 759$ vs. 53 recruits $/ \mathrm{m}^{2}$; medians, $n=20$ plots, Appendix C).

Three years after sowing, 20 of the 22 sown species were present at all three sites, between $15(\mathrm{P})$ and $19(\mathrm{~N})$ per plot (medians, $n=20$ plots). Between $11(\mathrm{~N})$ and 15 (S) species were introduced at the sites, resulting in increases in species richness between $32 \%(\mathrm{~N})$ and $61 \%$ (P). No resident species became locally extinct (data not shown).

\section{Site and year effects}

Emergence was high at San Giorgio (18 122 individuals, $41.2 \%$ of the sown seeds, sum over all species and years) and Negrentino (15118 individuals, 34.4\%) and low at Poma (9774 individuals, 23.8\%). Survival over three years of growing decreased from Negrentino (42.9\%) to San Giorgio (31.9\%) and Poma (17.2\%). Mortality was highest at Poma, mainly during summers (Fig. 1). The difference in survival between Negrentino and San Giorgio arose mainly from summer 2001 onwards in the 1999 plots. Three years after sowing, the total number of established individuals was dependent on site $\left(F_{2,27}=66.3, P<0.001\right)$ and was higher at Negrentino and San Giorgio than at Poma (Fig. 2a). This pattern was consistent for most of the single species (Table 1). Although establishment of half of the species was influenced by the year of sowing, either by a higher emergence of seedlings in the 1999 plots or a higher survival in the 1998 plots (Appendix D), there was no effect of year and site $\times$ year interaction on total number of established individuals.

Seedling growth differed considerably between sites (Table 1). It was lowest for 17 species at San Giorgio and highest for 18 species at Negrentino. Growing conditions at the sites were reflected by the number of species that reached reproductive stage: 14 species flowered at Negrentino, nine at Poma, but only three at San Giorgio. Growth of most species was not dependent on year of sowing. Annual phytomass of the individuals that emerged from the sown seeds (sum over all 22 species) reached $38.7 \%$ of the total phytomass of the sown plots at Negrentino, but only $7.7 \%$ at Poma and $1.8 \%$ at San Giorgio (Fig. 2b). Most of the total seedling phytomass was contributed by Anthyllis vulneraria $(31.3 \%)$, Hypochaeris radicata $(14.9 \%)$, Centaurea nigrescens (14.6\%), and Scabiosa columbaria (12.8\%) at Negrentino, by $C$. nigrescens $(48.9 \%)$ and Plantago 


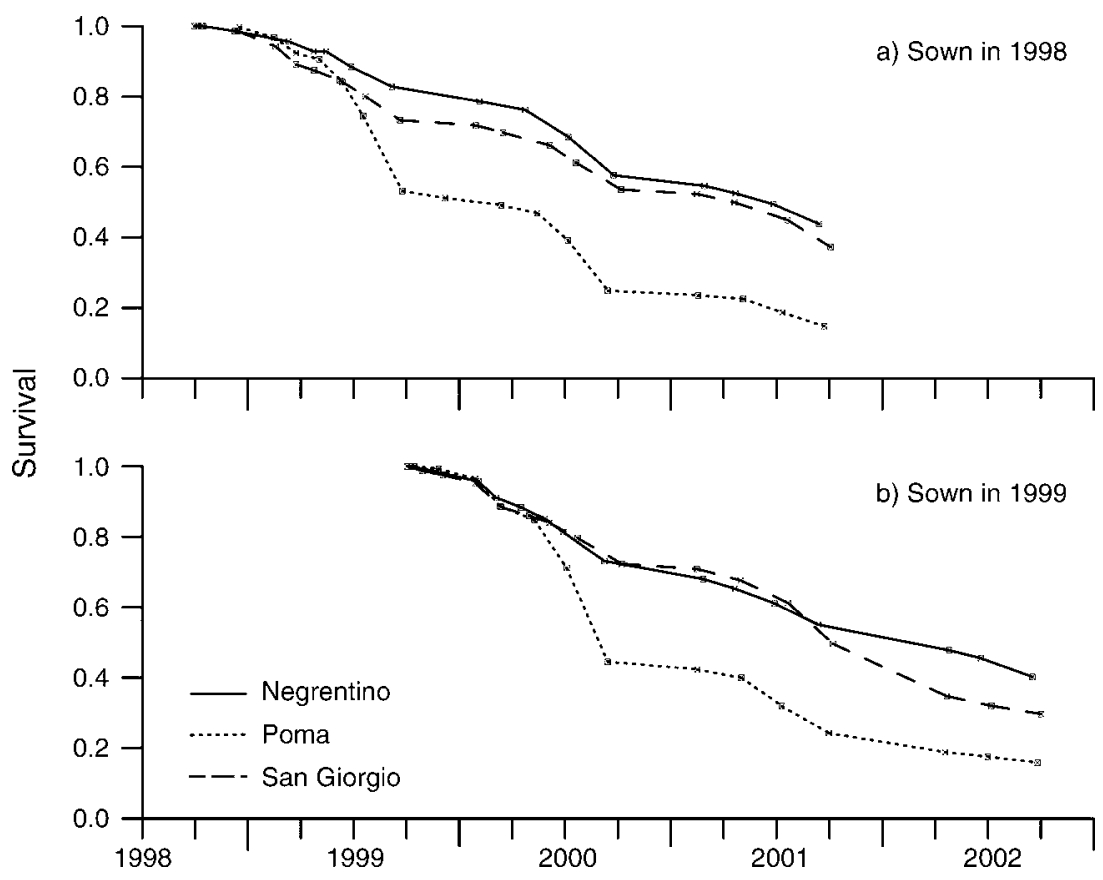

FIG. 1. Survival of the individuals emerging from the 22 species sown in (a) 1998 and (b) 1999 at three sites in southern Switzerland: Negrentino (solid line), Poma (dotted line), and San Giorgio (dashed line).

lanceolata $(31.3 \%)$ at Poma, and by $C$. nigrescens (48.9\%), P. lanceolata (13.6\%), and Sanguisorba minor $(9.7 \%)$ at San Giorgio.

\section{Effects of habitat quality within sites}

As the majority of the species showed consistent establishment success across single sites, effects of habitat quality on seedling recruitment were not tested for individual species. Total number of emerged seedlings was not affected by productivity, proportion of gaps and bare ground, or radiation at the three sites. At Negrentino seedling survival was positively influenced by radiation $\left(r^{2}=0.18 ; P<0.05\right)$, and seedling growth (mean mass per surviving individual) depended upon the combined effects of radiation and phytomass of the resident vegetation in the first years after sowing $\left(r^{2}=\right.$ $0.51 ; P<0.001$; radiation $t_{17}=4.15 ; P<0.001$; phytomass $\left.t_{17}=-2.65 ; P<0.05\right)$. At Poma, gap proportion positively influenced seedling survival $\left(r^{2}=\right.$ $0.23 ; P<0.001 ; n=20)$ and seedling growth $\left(r^{2}=0.29 ; P\right.$ $<0.01)$. Seedling survival and growth were not affected by productivity, proportion of gaps and bare ground, or radiation at San Giorgio.

\section{Interaction with resident vegetation}

As phytomass of individuals established from the sown seeds was low at Poma and San Giorgio, the influence of sowing on productivity (total annual phytomass) of the community was only tested for Negrentino. Annual phytomass of the plots showed no effect of sowing in the first summer after sowing, when the sown individuals contributed $12.9 \%$ of the annual phytomass (median, $n=20$ ). As annual phytomass in the first year after sowing was higher in the 1999 plots than in the 1998 plots $\left(F_{1,9}=25.2 ; P<0.001\right)$, it was included as a covariate to test the influence of sowing on productivity. This revealed that phytomass in the third year after sowing was affected by sowing $\left(F_{1,17}=21.1 ; P\right.$ $<0.001)$ and year $\times$ sowing interaction $\left(F_{1,17}=4.9 ; P<\right.$ $0.05)$, but not by year $\left(F_{1,8}=0.2 ; P>0.05\right)$. The plots sown in 1998 showed a significantly higher phytomass than the control plots, but not the plots sown in 1999 (Fig. 3). The difference between the plots sown in 1998 and 1999 was not due to the phytomass of the resident vegetation, which did not differ $\left(F_{1,8}=0.5 ; P>0.05\right)$, but to the individuals established from seeds sown, which showed a higher annual phytomass in the 1998 plots $\left(F_{1,8}=7.5 ; P<0.05\right)$. This is also reflected in the positive relationship between the increase in phytomass from the first to the third year after sowing and the phytomass of the individuals established from sown seeds $\left(r^{2}=0.82 ; P<0.001 ; n=20\right)$. There was no relationship between the phytomass of the resident vegetation and total phytomass of the sown individuals in the plots three years after sowing. The difference between the 1998 and 1999 plots in seedling phytomass was mainly due to the four fast-establishing species $A$. vulneraria, $H$. radicata, $C$. nigrescens, and $S$. columbaria (Appendix E), which showed high proportions of flowering individuals (Table 1).

The effect of sowing on productivity, which arose in the second year after sowing in 1998, was persistent across time (Fig. 4). Five years after sowing, sown plots still had a higher phytomass than control plots $\left(F_{1,9}=\right.$ 

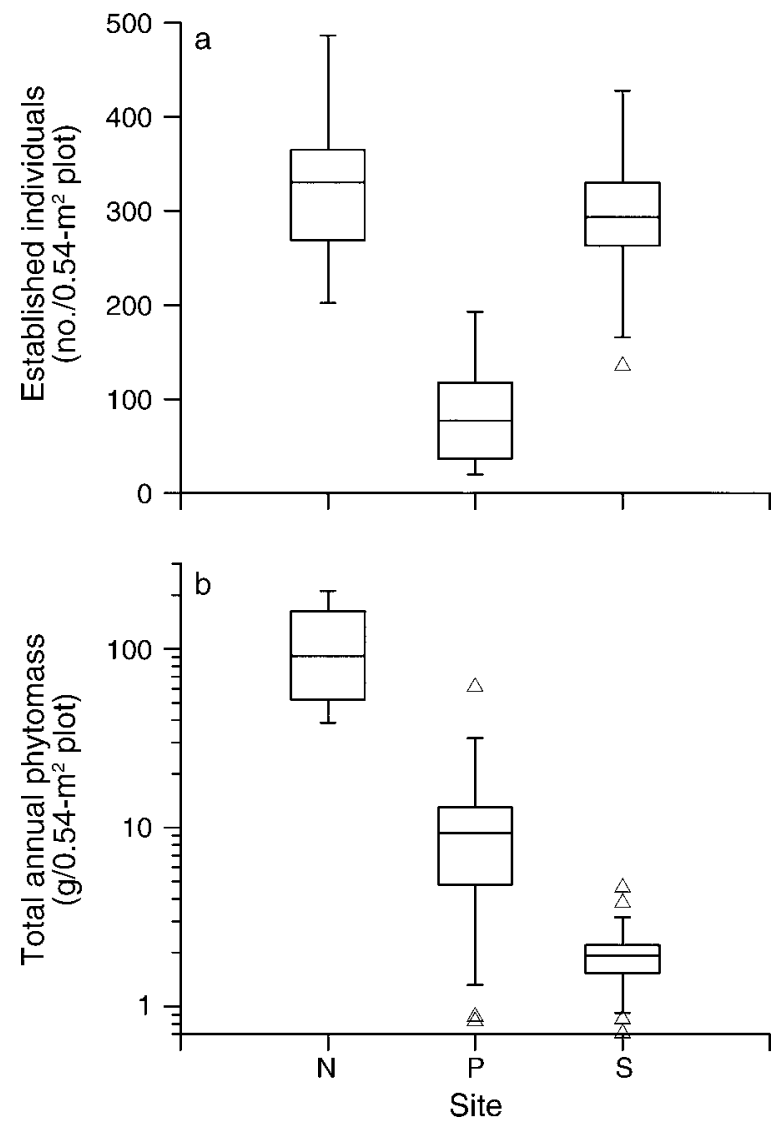

FIG. 2. Performance of sown species at three sites in southern Switzerland (N, Negrentino; P, Poma; S, San Giorgio): (a) number of established individuals and (b) total annual phytomass of sown plants (log scale) in the third year after sowing. Values in both panels are sums over all 24 populations $\left(n=20\right.$ plots; plot size $\left.0.54 \mathrm{~m}^{2}\right)$. Boxes show median and quartiles, with whiskers or triangles extending to data within inner or outer fences (hinges \pm 1.5 or $3 \times$ interquartile range).

6.7; $P<0.05)$. Individuals that emerged from sown seeds reached $33.1-42.1 \%$ of the total phytomass (medians, $n=10$ ) from the second year onwards. Species with the highest phytomass proportions, $A$. vulneraria in the second year, $A$. vulneraria and $H$. radicata in the third year, and $C$. nigrescens and S. columbaria in the fourth and fifth years, contributed half of this proportion.

\section{DISCUSSION}

Number and growth of surviving individuals of the majority of the sown species indicated seed limitation at all three sites, although seed limitation in the strict sense was only proven for the $14-59 \%$ of the sown species that flowered within three years after sowing. The regeneration niche for a few species did not exist at all sites, because low numbers and growth of survivors suggested that these species would die out in the future without any having reached the reproductive stage. Sowing seeds

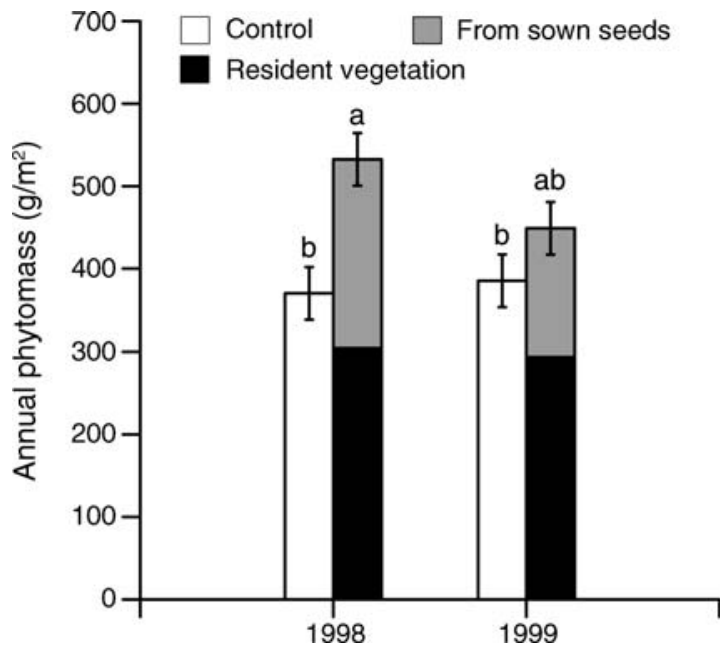

FIG. 3. Total annual phytomass in control (open bars) and sown plots (gray, individuals established from sown seed; black, resident vegetation) in the third year after sowing in autumn 1998 or 1999 at the Negrentino site in southern Switzerland (summed over two harvests in summer and autumn; means \pm sE, adjusted for covariate). Means without lowercase letters in common differed significantly $(P<0.01)$.

in these formerly abandoned meadows, at a density similar to natural seed rain in meadows, resulted in a $2-$ 15 times higher density of recruits. The density of emerged seedlings resembled the density of spontaneous seedlings in a nearby meadow at Negrentino (approximately 1400 seedlings $\mathrm{m}^{-2} \cdot \mathrm{yr}^{-1}$; A. Stampfli and M. Zeiter, unublished manuscript). The increase in species richness after sowing suggests that species richness of all three communities is dependent upon the size of the available propagule pool.

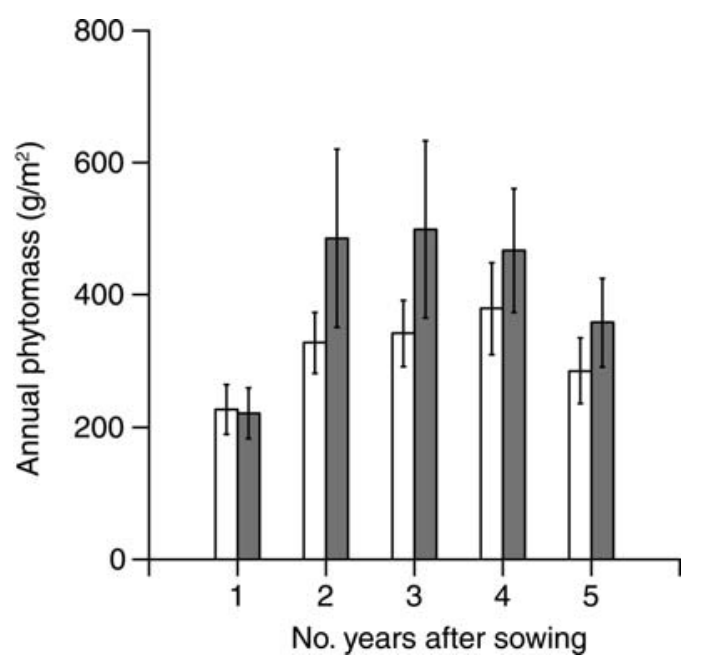

FIG. 4. Total annual phytomass in unsown (open bars) and sown plots (solid bars) in the first to fifth years after sowing in autumn 1998 at Negrentino (sums over the two harvests in summer and autumn; means $\pm \mathrm{SD}$ ). 


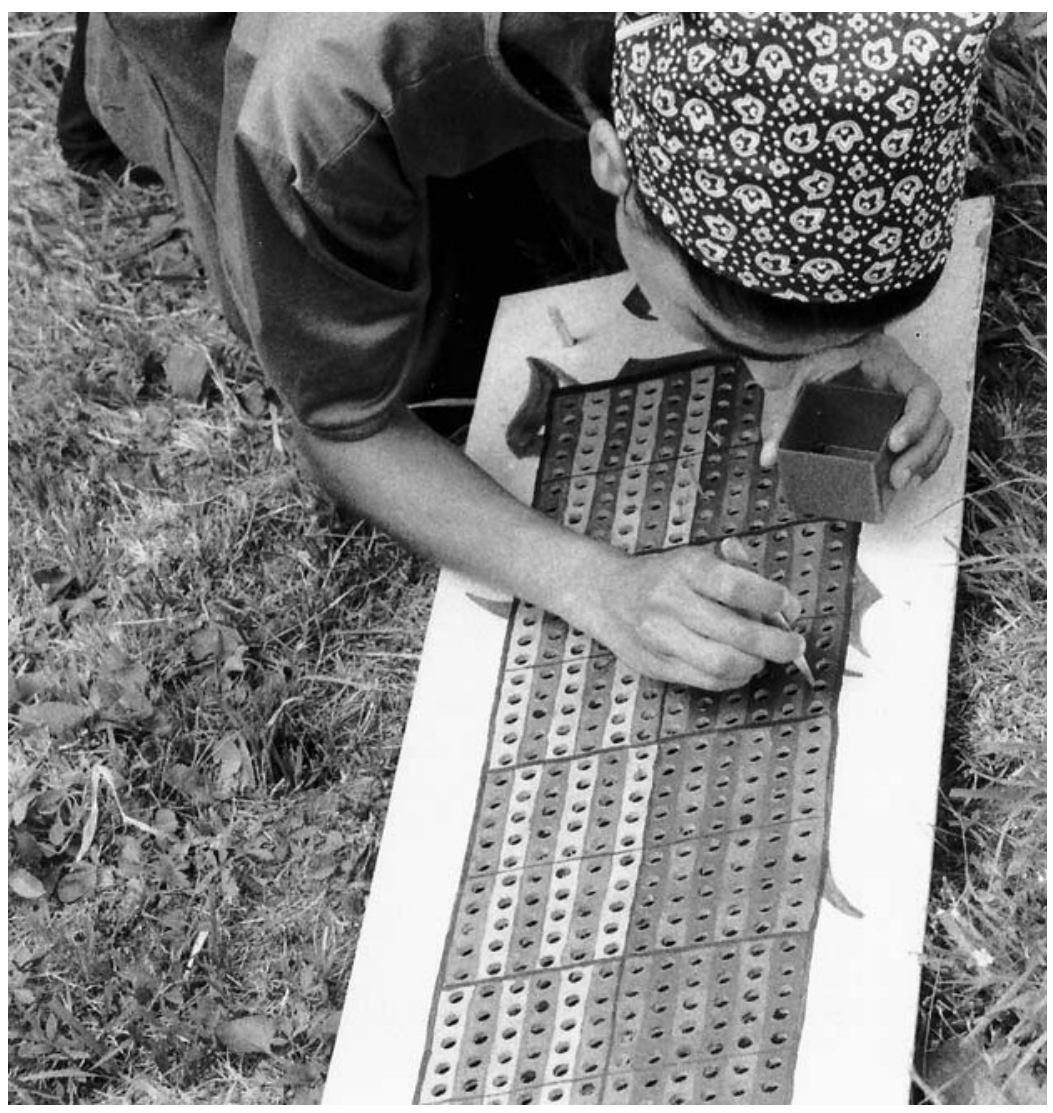

Plate 1. Seed addition to the mown grassland that has suffered a reduction in species richness over ten years of abandonment (Negrentino, southern Switzerland, September 1998). Photo credit: A. Stampfli.

Low numbers of established individuals at Poma and reduced growth at San Giorgio indicated stronger microsite limitation compared to Negrentino. The positive effect of radiation combined with the negative effect of the resident phytomass at Negrentino and the positive influence of gap density at Poma is consistent with the idea that competition from established plants limits recruitment at these sites. Different measures of competitive release, phytomass and gap proportion, reflect different limiting resources: light at Negrentino and water and soil minerals at Poma. At Poma, water limitation was not due to lower precipitation, but to a low water storage capacity of the soil, and soil minerals in the relatively acid soil included a high aluminum concentration that could have led to toxic effects. Recruitment limitation at San Giorgio, indicated by the slow growth of the sown species, might have been due to nutrient deficits $(\mathrm{P}, \mathrm{Fe})$ in this soil of high $\mathrm{Ca}$ content. The slow growth at San Giorgio was partly due to the origin of seeds as only four sown species originated from this site (Appendix B), and local adaptation in one, Bromus erectus, has been shown to positively influence recruitment (M. Zeiter, A. Stampfli, and D. M. Newbery, unpublished manuscript). Additional experiments in which water levels, soil chemistry, and vegetation density/canopy cover are manipulated would be needed to confirm these causal relationships. Moreover, the unknown composition of arbuscular mycorrhizal fungi (Moora and Zobel 1998, van der Heijden 2004) needs to be investigated, as this may have modified differences in recruitment success between Negrentino and the other sites.

Limited productivity of the resident vegetation at Negrentino resulted, in part, from a reduced density of plants in the years after mowing was resumed. Sowing seeds in regular small spaces obviously augmented plant density. Limited productivity was particularly due to a lack of fast-growing populations of short-lived perennials (Anthyllis vulneraria, Hypochaeris radicata). Seedlings of these species use resources more efficiently during the early growing season than species of the resident vegetation. Plant density and community productivity were maintained at higher levels over time because these species were replaced by slowly maturing, long-lived perennials, which probably took advantage of extra nitrogen provided from the legume A. vulneraria. The decrease in difference in productivity between sown and control plots over time may have been due to the diminishing effect of a one-time seed addition on the cumulative seed rain falling on the plots. 
Sowing in different years had an effect on productivity of the community at Negrentino caused by a lower phytomass of the individuals established from sown seeds in the 1999 plots, mainly those of the fast-growing species A. vulneraria, Centaurea nigrescens, $H$. radicata, and Scabiosa columbaria. This year effect was not due to seed mass (Appendix B), and weather conditions after sowing were favorable in both years. Increased growth of the resident vegetation in the growing season before seed addition was due to a more balanced availability of soil moisture in 1999 that resulted in a presumably stronger competitive effect on seedling emergence and/or seedling growth. As the strong growth of the fast-growing sown species in the second and third years after sowing compensated for the reduced growth of the resident vegetation in the 1998 plots, many slowly growing species did not differ in their seedling growth between plots sown in 1998 and 1999.

Productivity of the grassland was not only restricted by seed limitation, but also by a negative feedback effect of high growth in favorable years on productivity in the following years by means of reduced growth of the recruiting populations. The increase in productivity due to sowing can be interpreted as a higher invasibility of the community after a dry year providing more light for seedling growth. This is consistent with the idea that colonizations that cause changes at the community level depend on a supply of seeds of a variety of species that are able to exploit temporary resource surpluses (Davis et al. 2000, Tilman 2004). Grace (2001) stressed the importance of shading as the mechanism whereby community biomass may suppress recruitment, and some studies have shown positive relationships between seedling biomass and light transmittance in the resident vegetation (Jutila and Grace 2002), especially in the first weeks of seedling development (Milbau et al. 2003).

While several studies have shown that the effect of seed limitation on community properties such as species richness and measures of productivity is less important in more productive sites (Burke and Grime 1996, Foster 2001, Wilsey and Polley 2003, Xiong et al. 2003, Stevens et al. 2004), this study shows that even with small increases in the annual productivity the influence of seed limitation on a community decreases. At the two sites with more harsh environmental conditions the influence of seed limitation on productivity was very low. This is consistent with the idea that abiotic conditions affect community composition under conditions of severe stress (e.g., drought; Wilsey and Polley 2003) and that the role of species availability should be greatest in sites of moderate productivity, but will decline in importance with a shift from moderate to high productivity, due to the increasing relevance of competitive exclusion (Grime 1979, Huston 1999).

\section{ACKNOWLEDGMENTS}

This work was supported by grants from the Swiss National Science Foundation (31-55917.98, 3100A0-100612). We appreciate that Angelo Gropetti and the Chiesa Parrociale di
Prugiasco accepted the establishment of permanent plots on their property. We thank Andreas Rüegger and Silvia Zanetti (Agroscope FAL Reckenholz, Zürich) for performing the germination tests and Roman Zweifel for the simulation model of soil water potential.

\section{Literature Cited}

Barot, S. 2004. Mechanisms promoting plant coexistence: Can all the proposed processes be reconciled? Oikos 106:185-192.

Burke, M. J. W., and J. P. Grime. 1996. An experimental study of plant community invasibility. Ecology 77:776-790.

Davis, M. A., J. P. Grime, and K. Thompson. 2000. Fluctuating resources in plant communities: a general theory of invasibility. Journal of Ecology 88:528-534.

Egli, P., and B. Schmid. 2001. The analysis of complex leaf survival data. Basic and Applied Ecology 2:223-231.

Ellenberg, H. 1996. Vegetation Mitteleuropas mit den Alpen. Fifth edition. Ulmer, Stuttgart, Germany.

Eriksson, O., and J. Ehrlen. 1992. Seed and microsite limitation of recruitment in plant populations. Oecologia 91:360-364.

Foster, B. L. 2001. Constraints on colonization and species richness along a grassland productivity gradient: the role of propagule availability. Ecology Letters 4:530-535.

Foster, B. L., and T. L. Dickson. 2004. Grassland diversity and productivity: the interplay of resource availability and propagule pools. Ecology 85:1541-1547.

Foster, B. L., T. L. Dickson, C. A. Murphy, I. S. Karel, and V. H. Smith. 2004. Propagule pools mediate community assembly and diversity-ecosystem regulation along a grassland productivity gradient. Journal of Ecology 92:435-449.

Foster, B. L., and D. Tilman. 2003. Seed limitation and the regulation of community structure in oak savanna grassland. Journal of Ecology 91:999-1007.

Grace, J. B. 2001. The roles of community biomass and species pools in the regulation of plant diversity. Oikos 92:193-207.

Grime, J. P. 1979. Plant strategies and vegetation processes. John Wiley and Sons, Chichester, UK.

Huston, M. A. 1999. Local processes and regional patterns: appropriate scales for understanding variation in the diversity of plants and animals. Oikos 86:393-401.

Jutila, H. M., and J. B. Grace. 2002. Effects of disturbance on germination and seedling establishment in a coastal prairie grassland: a test of the competitive release hypothesis. Journal of Ecology 90:291-302.

Kupferschmid, A. D., A. Stampfli, and D. M. Newbery. 2000. Dispersal and microsite limitation in an abandoned calcareous grassland of the southern Prealps. Folia Geobotanica 35: $125-141$.

Lauber, K., and G. Wagner. 1996. Flora Helvetica. Haupt, Bern, Switzerland.

McCullagh, P., and J. A. Nelder. 1989. Generalized linear models. Second edition. Chapman and Hall, London, UK.

Milbau, A., I. Nijs, L. van Peer, D. Reheul, and B. de Cauwer. 2003. Disentangling invasiveness and invasibility during invasion in synthesized grassland communities. New Phytologist 159:657-667.

Moora, M., and M. Zobel. 1998. Can arbuscular mycorrhiza change the effect of root competition between conspecific plants of different ages? Canadian Journal of Botany 76:613619.

Mouquet, N., P. Leadley, J. Meriguet, and M. Loreau. 2004. Immigration and local competition in herbaceous plant communities: a three-year seed-sowing experiment. Oikos 104:77-90.

Payne, R. W. 2000. The guide to Genstat. Lawes Agricultural Trust, Rothamsted, UK.

Silvertown, J. W., and J. B. Dickie. 1980. Seedling survivorship in natural populations of nine perennial chalk grassland plants. New Phytologist 88:555-558.

Stampfli, A. 1992a. Effects of mowing and removing litter on reproductive shoot modules of some plant species in 
abandoned meadows of Monte San Giorgio. Botanica Helvetica 102:85-92.

Stampfli, A. 1992b. Year-to-year changes in unfertilized meadows of great species richness detected by point quadrat analysis. Vegetatio 103:125-132.

Stampfli, A., F. Guggisberg, S. Berli, and H. Pestalozzi. 1994. The abandoned Danthonia alpina-grasslands on Monte San Giorgio: evidence of floristic changes and suggested management practices. Dissertationes Botanicae 234:59-78.

Stampfli, A., and M. Zeiter. 1999. Plant species decline due to abandonment of meadows cannot easily be reversed by mowing. A case study from the southern Alps. Journal of Vegetation Science 10:151-164.

Stampfli, A., and M. Zeiter. 2004. Plant regeneration directs changes in grassland composition after extreme drought: a 13-year study in southern Switzerland. Journal of Ecology 92:568-576.

Stevens, M. H. H., D. E. Bunker, S. A. Schnitzer, and W. P. Carson. 2004. Establishment limitation reduces species recruitment and species richness as soil resources rise. Journal of Ecology 92:339-347.

Tilman, D. 1997. Community invasibility, recruitment limitation, and grassland biodiversity. Ecology 78:81-92.

Tilman, D. 2004. Niche tradeoffs, neutrality, and community structure: a stochastic theory of resource competition, invasion, and community assembly. Proceedings of the National Academy of Sciences, USA 101:10854-10864.

Turnbull, L. A., M. J. Crawley, and M. Rees. 2000. Are plant populations seed-limited? A review of seed sowing experiments. Oikos 88:225-238.

van der Heijden, M. G. A. 2004. Arbuscular mycorrhizal fungi as support systems for seedling establishment in grassland. Ecology Letters 7:293-303.

Walter, H., and H. Lieth. 1964. Klimadiagramm Weltatlas. Alpenraum. Fischer, Jena, Germany.

Wilsey, B. J., and H. W. Polley. 2003. Effects of seed additions and grazing history on diversity and productivity of subhumid grasslands. Ecology 84:920-931.

Xiong, S. J., M. E. Johansson, F. M. R. Hughes, A. Hayes, K. S. Richards, and C. Nilsson. 2003. Interactive effects of soil moisture, vegetation canopy, plant litter and seed addition on plant diversity in a wetland community. Journal of Ecology 91:976-986.

Zobel, M., and R. Kalamees. 2005. Diversity and dispersalCan the link be approached experimentally? Folia Geobotanica 40:3-11.

Zobel, M., M. Otsus, J. Liira, M. Moora, and T. Mols. 2000. Is small-scale species richness limited by seed availability or microsite availability? Ecology 81:3274-3282.

\section{APPENDIX A}

A table showing habitat quality and soil conditions at the three study sites in southern Switzerland (Ecological Archives E087055-A1)

\section{APPENDIX B}

A table showing the sown species, their provenances, results of seed mass measurements, methods and results of germination tests, and the occurrence of established populations in the study sites (Ecological Archives E087-055-A2).

\section{APPENDIX C}

A table showing establishment success of seedlings emerged from the soil seed bank at the three study sites two years after beginning the experiments in 1998 or 1999 (Ecological Archives E087-055-A3).

\section{APPENDIX D}

A table showing the effects of sowing year and year $\times$ site interaction on the performance of the sown species three years after sowing (Ecological Archives E087-055-A4).

\section{APPENDIX E}

A table showing the performance of 22 species three years after sowing in 1998 and 1999 at Negrentino (Ecological Archives E087-055-A5). 